\title{
APRESENTAÇÃO DAS MÚLTIPLAS FACES DA FERTILIDADE: PENSANDO UMA ANTROPOLOGIA DOS ÚTEROS
}

Giovana Acacia Tempesta (giovana.tempesta@gmail.com/UnB);

Rosamaria Giatti Carneiro (rosacarneiro@unb.br/UnB);

Soraya Resende Fleischer (soraya@unb.br/UnB)

Era o começo da noite de uma terça-feira de verão em Brasília. Giovana e Rosamaria foram até a casa de Soraya para discutirem como alinhavar o texto que apresentaria o Dossiê “Antropologia dos Úteros". Apostaram que, entre xícaras de chá e fatias de apple crumble (uma torta de maçã express que a avó de Soraya fazia muito), conseguiriam criar um ambiente mais inspirador para que as ideias fluíssem. Para esse arranjo funcionar, aproveitaram justamente o horário em que a filha de Giovana estava na aula de natação, que o filho de Rosa poderia ser cuidado por seu companheiro e que a filha de Soraya estava voltando da colônia de 
férias. Essas mães acadêmicas precisavam organizar toda uma logística doméstica coletiva para conseguirem trabalhar.

Rosa, bem a seu estilo, logo lançou uma de suas ótimas provocações.

Rosa: Essa apresentação precisa contextualizar de onde nós três viemos, de onde essa Antropologia dos úteros começou a ser gestada. O que vocês acham?

Soraya: Boa ideia! Posso começar. Durante meu doutorado, eu pesquisei o parto domiciliar numa região ribeirinha no Pará. Na pequena e empobrecida cidade de Melgaço, onde quase $70 \%$ das crianças nasciam em casa, eu fui conviver, conhecer e entender o trabalho oferecido pelas parteiras da região, em especial o de Dona Dorca, à época a mais famosa e atuante "aparadeira”, como a chamavam. Mais recentemente, diante da epidemia do vírus Zika, eu e a Rosa começamos um projeto de pesquisa no Recife, para acompanhar as suas consequências nos últimos anos sobre as crianças e também sobre as mães e suas famílias. E, em fins de 2016, a Daniela Manica, naquele tempo professora da UFRJ (hoje de volta à Unicamp), me convidou para contar sobre essa nova pesquisa num evento de nome muito sugestivo, "Estranhas entranhas". Durante dois dias, discutimos o que ela e suas colegas denominaram de "as múltiplas ontologias do útero". Lá no Rio de Janeiro, ouvimos outras pesquisadoras contarem sobre parto, menstruação, saúde feminina, maternidade. Voltei superinspirada com a polissemia criativa que a ideia de "útero" poderia gerar e animada para pensar como essa ideia aproximava tantas e diferentes pesquisas que vínhamos fazendo, inclusive aqui dentro da $\mathrm{UnB}$.

Rosa: A minha história com o tema é mais ou menos assim ... há uns 12 anos, vivia em Buenos Aires, onde cursava um Diplomado em Estudios de Género junto a Universidad de Ciencias Economicas e Sociales e uma Especialização em Género y Teoria Psicoanalitica pela Universidad de San Martin, quando descobri o grupo La Rueda Purpura. Eram mulheres que queriam, entre outras coisas, parir sem nenhuma intervenção, sentindo tudo. Bem intrigada com esse desejo, decidi voltar ao Brasil, em 2007, com uma pesquisa de doutorado em meus braços: compreender os porquês de algumas mulheres buscarem um parto cru em pleno século 21. Foram os anos mais incríveis de minha vida. Depois disso, o parto e a maternidade me entranharam ou se entranharam em mim como tema de trabalho, até que, entre 2014 e 2015, vivi tudo na pele e em meu corpo, quando gestei e trouxe a esse mundo um outro ser. Se os úteros sempre me interessaram desde o mestrado, com meu engajamento feminista, depois do doutorado e de meu filho, me vi convencida de sua intensidade reflexiva e de sua capacidade de expansão.

Giovana: Bom, fui formada na etnologia indígena e as questões referentes ao corpo e às relações por ele mediadas me interessam desde a época da graduação em Ciências Sociais. Desde que engravidei, em 2014, comecei a estudar sobre gestação, parto, puerpério e maternidade e minha experiência pessoal de dar à luz acabou sendo atravessada pela minha convivência com povos indígenas ama- 
zônicos. Ainda durante o puerpério percebi que essa experiência me suscitava indagações de cunho antropológico, com fortes implicações éticas, políticas e estéticas. Então, quando Soraya e Rosa me falaram sobre o curso, fui tomada por um sentimento de encantamento arrebatador e me dispus a colaborar com o processo de nutrição desse projeto, assim como com o processo de gestação deste Dossiê que agora vem à luz.

Rosa: Então, foi bem nessa época do evento "Estranhas entranhas" que a Soraya me instigou a pensar sobre um curso de pós-graduação para tratar das possibilidades do útero no plural. Queríamos propor algo não fisicalista e tampouco essencialista, inédito mesmo nos programas de pós-graduação; com recorte de gênero e que versasse sobre mães, corpos, controle estatal, criatividade, movimentos de resistência, feminismos e deficiência, já que também estávamos no início de nosso projeto sobre o cotidiano das mães de crianças com microcefalia no Recife. Por isso, logo de saída, pensamos em três eixos ou blocos de leitura: o controle dos úteros, a maternidade em contextos de deficiência e movimentos de mulheres mães.

Soraya: É muito bacana como os encontros e as provocações mútuas vão nos permitindo criar novas oportunidades de diálogo, não é? Eu e Rosa já trabalhávamos juntas, eu já conhecia Daniela de muito tempo e tinha vontade de ler a tese dela integralmente. Nesse ínterim, Giovana, que já conhecia Rosa, se aproximou do Departamento de Antropologia. A partir daí, não paramos mais de inventar moda, sempre criando outras desculpas para pensar, estudar e escrever juntas. Pois o curso abriu com a tese de Daniela Manica sobre os experimentos clínicos realizados, em sua maioria, sobre corpos de mulheres negras por um ginecologista baiano, Elsimar Coutinho, durante décadas do século XX. Esse foi um texto perturbador, assim como as outras cinco etnografias que nos propusemos a ler, cada uma a seu modo. A turma, para nossa surpresa, adorou o texto escrito de modo mais convencional de Lilian Chazan. Depois se emocionou com as histórias de crianças doentes e maternidades envolvidas na pesquisa de Cheryl Mattingly (comunidades negras de classe popular na Califórnia cuidando de crianças com doenças crônicas e graves), de Isis Araújo (crianças “deficientes” entre os Karitiana) e de Fabiana Oliveira (mães e pais testando o uso do canabidiol nas convulsões refratárias de seus filhos). E fechamos o curso com a premiada etnografia de Paula Lacerda sobre o movimento de mães no interior paraense, buscando memória, dignidade e justiça para seus filhos torturados e assassinados.

Rosa: Ficamos surpresas quando apareceram quinze estudantes interessadas no tema do curso, um contingente alto para um curso de pós-graduação. Em nossa avaliação, a turma se conectou muito com o curso, tanto com a proposta de lermos etnografias recentes de forma integral, quanto com os conteúdos, tão relacionados com diferentes modos de viver a maternidade, de exercer a reprodução, de cuidar e ter a saúde cuidada. Achamos que todas ficaram bem mexidas, 
provocadas por ideias pouco discutidas no âmbito acadêmico e mesmo no âmbito pessoal. Além de nós, somente uma outra estudante era mãe e uma estava nos primeiros meses de gestação. Mas todas eram filhos e filhas, cuidadores e cuidadoras. Quer dizer, apostamos e percebemos que seria possível experimentar o universo dos úteros a partir de alguma perspectiva.

Giovana: Também acho que a conexão se deu porque vocês investiram num curso que teve um lado muito prático, muito hands on. Logo na primeira aula, vocês nos convidaram a desenhar. Imagina, desenhar num curso de Antropologia! A proposta era registrar com imagens, traços e cores o que entendíamos pela palavra "útero". Foi uma chance de fazer os significados virem à tona, se diversificarem e se misturarem e, de modo geral, embalarem o curso até o seu final. Além disso, houve uma prática diária e continuada de escrita, não apenas de leitura das teses. Tivemos uma quinzena para ler e nos dedicar a cada obra, o que é raro no ritmo frenético que se convencionou nos cursos de pós-graduação. Como dito, eram todos textos muito (in)tensos emocionalmente, difíceis de serem lidos de modo muito rápido ou desapegado. Depois, na segunda aula dedicada a cada etnografia, tínhamos que levar para a sala de aula uma resenha daquela obra (ou "síntese reflexiva", como foi apelidado pelas professoras) - de apenas três páginas. E vocês propunham que esses pequenos textos fossem aproveitados durante a aula, não somente como um elemento de avaliação. Quer dizer, já era uma produção de conhecimento e não meramente uma etapa didática a cumprir. Em alguns dias, trocamos os textos e tivemos a chance de conhecer como a colega tinha entendido o livro e escrito seu texto. Em outros dias, começávamos a aula relendo o nosso próprio texto para retomar a obra e podermos contribuir com mais frescor no debate. Por vezes, tínhamos que ler o texto da colega, sublinhar e encontrar uma frase para discutir na aula. E por aí fomos. Apostar em pequenas e ritmadas doses de escrita ao longo do semestre (em vez de um único exercício de escrita ao final desse período) permitiu que a turma se conhecesse um pouco mais, que o conteúdo da aula fosse também produzido por nós, que nossas fragilidades e também habilidades pudessem circular. Ao longo do semestre prevaleceu um clima de acolhimento, colaboração, criatividade, respeito e generosidade intelectual - inclusive com as autoras selecionadas, cujas etnografias foram lidas integralmente. Era prazeroso ir para as aulas/encontros, todos queriam participar, pensar a partir das leituras e todas saímos ainda mais provocadas. Poucas vezes havia visto um curso assim, tão denso teoricamente e tão leve na maneira como as pessoas interagiam. O compartilhamento de referências bibliográficas, sites e eventos relacionados à temática do curso foi uma demonstração particular da efervescência das reflexões geradas em sala de aula. Por fim, acho que o envolvimento da turma se deu também porque houve uma conexão pessoal com o tema do curso. Em alguma medida, todas ali aproveitaram para trabalhar questões pessoais. Houve mesmo uma relação biográfica com o tema mais geral e os trabalhos finais, reunidos agora nesse Dossiê, nos revelam isso claramente. 
Acho que todas fomos afetadas pelos textos e, no meu caso, a intensidade afetiva das trocas em sala de aula levaram à reconfiguração do meu projeto de pesquisa, num sentido próximo ao proposto por Jeanne Favret-Saada, uma vez que assumi o risco de embarcar na aventura proposta por Soraya e Rosa e, assim, passei a estranhar modos de fazer antropologia que me eram tão familiares, ao passo que me aproximei de outras possibilidades e outros desafios teóricos, metodológicos, epistemológicos, literários, éticos e políticos. No início do curso, meu estilo de escrita era mais quadrado (ou canônico); porém ao longo do semestre fui me deixando interpelar pelas proposições críticas de Soraya, Rosa e das colegas, e assim passei a questionar alguns pressupostos do estilo de pensamento logocêntrico. Sob o impacto das discussões em sala de aula, das novas leituras, do contexto etnográfico da minha pesquisa e da reflexão sempre renovada sobre minha própria experiência de gestação, parto, puerpério e maternagem, abracei (inicialmente sem o saber) uma ideia que Daniela Manica recupera da obra de Teresa Joaquim, no artigo que abre este Dossiê: "Mas a abstracção talvez não seja a do 'corpo abstracto' mas antes a duma lógica em que experiências diversificadas, e o corpo e a palavra, a denegação e o reconhecimento, sejam possíveis, em que 'pensar seja criar possíveis' (Joaquim 1997: 451) (ênfase adicionada)."

Soraya: Como se referiam a livros bastante recentes, algumas das resenhas foram revisadas e publicadas em periódicos da Antropologia, mas também da Saúde Coletiva e da Psicologia. Quer dizer, um material desse tipo acaba tendo várias utilidades para uma estudante de pós-graduação: para acompanhar a sala de aula, como etapa preliminar na preparação de um texto maior (como um artigo ou uma dissertação, por exemplo) e também como uma oportunidade de aprender a navegar pelo mercado editorial e já incrementar seu currículo.

Rosa: Ah, é bom lembrar que também apareceu com força logo no começo do curso a questão racial. Fomos interpeladas pela ausência da reflexão sobre raça/ cor nas etnografias estudadas. Em algumas delas, o assunto era abordado de maneira indireta ou muito rapidamente. E ora ... nos diziam as estudantes: o corpo da mulher negra é alvo de maior controle e de abandono estatal, vide as esterilizações em massa e os altos índices de mortalidade materna; as mães negras são as mais estigmatizadas e vistas como poliqueixosas; conduzem suas famílias via de regra sozinhas e ainda são responsabilizadas por muitas das mazelas sociais por não terem criado bem seus filhos. Foram as estudantes que demarcaram esse território, nos fizeram pensar e criticar os trabalhos lidos, nos impeliram a rever os textos e pediram atenção de toda a turma para isso, pautando o assunto texto a texto e nos convencendo de seus valiosos argumentos. Concordamos com essas demandas e é por isso, inclusive, que abrimos este Dossiê com dois artigos que tensionam claramente a relação entre mulheres, antropologia, maternidade e raça.

Giovana: Questões de classe e etnicidade também foram observadas e debatidas em sala de aula, pois, em interseção com a questão racial, compõem os meandros 
do mosaico etnográfico formado pelas diversas mulheres retratadas nos textos. Nas etnografias estudadas, ganhou destaque a ideia da permeabilidade simbólica do útero, na medida em que em todos aqueles contextos a noção de útero implicava entrecruzamentos de projeções, anseios, prescrições, dilemas morais, lutas políticas e conflitos - com parentes, profissionais de saúde, leis, instituições, além de ideias e imagens hegemônicas sobre saúde, doença, deficiência, cuidado, pessoa, ativismo, maternidade. Tudo o que lemos e elaboramos durante o curso nos conduz a um conjunto bastante diverso de modos de atualizar, encarnar, alargar e subverter conceitos mais convencionais, o que nos convida a ensaiar abordagens mais inventivas e arejadas para temas por vezes considerados controversos ou pouco nobres na seara da antropologia.

Rosa: Foi fascinante perceber mais um desdobramento do curso - as possibilidades e os estranhamentos perante os modos possíveis de se escrever uma etnografia. Estivemos entre modelos mais clássicos de escrita, com introdução, apresentação do arcabouço teórico, campo em seus muitos temas, como vimos com o texto de Lilian Chazan, mas também entre textos quase em forma de literatura de ficção, como o de Daniela Manica, e de cunho jurídico-policial, como o de Paula Lacerda. As estudantes estranharam as maneiras divergentes, sentiram falta de uma apresentação detalhada do texto, discordaram das escolhas das autoras. Mas ao final se viram provocadas a escrever os seus próprios textos de outras formas, iniciando por cenas, colocando-se a si mesmas como partícipes e se aventurando a comunicar o universo etnografado criativamente. Essa inflexão me tocou particularmente. Fui aquela que constantemente apontava que podemos explorar outras escritas, sobretudo as mulheres, pois temos um modo de escrever, por vezes, atravessado por nossas vidas pessoais, sobretudo quando o tema é maternidades, partos, movimentos e feminismos. Vimos, depois, como tudo isso rendeu nos trabalhos finais e na escrita das resenhas a serem entregues, depois de lida cada etnografia. Mais porosas, abertas e inusitadas, sem com isso perderem consistência objetal e teórica.

Giovana: Quero lembrar também que há conexões evidentes entre o curso, este Dossiê e a região Amazônica. Uma das estudantes do curso, Cibelle Canto, vem do Amapá e sobre a realidade das mulheres desse estado ela escreveu seu artigo que aqui incluímos. A reflexão que a Soraya faz começou lá pelos idos de 2004, quando ela transitou como pesquisadora pelas casas e mãos das parteiras do Pará marajoara. Uma das etnografias lidas durante o curso, de Paula Lacerda, se refere à sua pesquisa realizada em Altamira, Pará; escrevi uma resenha deste livro, que foi publicada num periódico colombiano; outra resenha do mesmo livro, escrita pela Andreza Benila, foi publicada no Anuário Antropológico, a revista de nosso Departamento de Antropologia da UnB. Há toda uma realidade uterina das paragens amazônicas que transparece nas nossas trajetórias, no curso e agora neste Dossiê, fazendo sentido termos buscado a revista Amazônica para poder divulgar esse conjunto de ideias. 
Rosa: Falando nisso, vale a pena apresentar brevemente os seis artigos aqui reunidos. Depois de selecionarmos os artigos para este Dossiê, todos em interlocução com a proposta da disciplina, vimos que girávamos ao redor de três eixos: o controle dos úteros das mulheres negras; o ativismo virtual de mães ao redor do parto e a luta de mães em nome de seus filhos considerados raros ou deficientes. Nos textos de Andreza e Bruna nos vemos entre as pesquisas que recaíram e fizeram uso desmedido e violento principalmente dos úteros das mulheres negras, seja analisando suas células, seja versando sobre os seus processos de aleitamento, apontando a importância de se reconhecer a dimensão racial quando se pensa sobre úteros, pesquisas e maternidades. Cibelle e Giovana nos levam ao ativismo materno nas redes, às denúncias de violência e às múltiplas possibilidades de viver e significar o parto, ainda que em contextos diversos, um mais situado e outro mais global, apresentando-nos escalas. Por último, Júlia, por meio das mães de filhos mortos com doenças raras e André com o debate das múltiplas acepções de deficiência no contexto pernambuco de Zika Vírus, redirecionam o nosso olhar para a política gerada a partir de filhos considerados atípicos ou desviantes. Sendo assim, úteros em seu interior, produtos uterinos e seus dilemas e do corpo para as ruas, em nome das transformações. De algum modo, esses artigos e este Dossiê se somam ao que temos pensado como um campo da antropologia brasileira: a antropologia do parto, que cresce e ganha contornos a partir dos anos 2000. Acrescentamos, nesse oportunidade, mais uma ponta para esse debate, pensarmos úteros, mas também maternidades no plural. A maternidade também passou a ocupar a agenda da antropologia mais recente, ao menos de modo concentrado; exemplo disso foi a criação da Remafes - Rede de Estudos sobre Maternidades e Feminismos, uma comunidade no Facebook, em agosto de 2017, durante o Simpósio Temático coordenado por mim e por Simone Diniz no 13..$^{\circ}$ Mundos de Mulheres \& Fazendo Gênero 11. Por isso, vemos aqui, e a partir da provocação de nossos estudantes, uma grande contribuição.

Soraya: Eu queria, por fim, deixar alguns agradecimentos importantes. Primeiro, é sempre um prazer trabalhar com a Rosamaria. Ela me provoca todos os dias em que me encontra, contando histórias que eu desconheço, me convidando a pensar em coisas que eu acho difíceis, mas necessárias, me acolhendo em minhas angústias mais remotas e indizíveis. Segundo, tem sido superestimulante trabalhar com a Giovana, que foi um presente que a Rosa ofereceu a mim e ao Departamento de Antropologia da UnB (DAN), e que traz uma energia criativa e criadora muito pertinente para a Antropologia, o feminismo, a sala de aula. Agradeço também por ela ter capitaneado a organização do presente Dossiê, na comunicação mais direta e amiúde com as autoras e com as editoras do periódico. A turma, que apostou que "úteros" seria um baita tema, nos insuflou com entusiasmo, envolvimento e afeto. O DAN tem permitido que aulas sejam dadas em coletivo, que a liberdade de cátedra e de didática se mantenha como ingrediente básico da boa universidade. A Daniela Manica, amiga de tantos anos, 
que produz uma Antropologia engajada e pertinente, provoca nossos alicerces com uma fina academia feminista. Daniela, lá atrás, com o evento que organizou na UFRJ, começa toda essa conversa; depois ela abre o curso com sua tese de doutorado; e agora fecha esse ciclo com o artigo que escreveu especialmente para este Dossiê. Mas ressalto que ela tem me proposto diálogos para além da Antropologia, como, por exemplo, ao me apresentar a escritora italiana Elena Ferrante e suas análises que escarafuncham fundo a maternidade que tenho criado dentro de mim. Somos gratas à revista Amazônica, na figura da colega antropóloga Profa. Érica Quinaglia, que rápida e animadamente acolheu nossa proposta. E, por fim, à Bruna Pratesi, que participou ativamente da turma, contribuiu aqui com um artigo e também nos brindou com um bordado que foi sendo produzido ao longo do curso. Essa iniciativa espontânea reúne algumas das sínteses possíveis que propusemos ao longo daquele semestre, entre uma antropologia dos úteros, das maternidades e das imagens. Ela aceitou gentilmente que sua obra de arte estampasse a capa desse número da revista, já convidando a todas para entrar, ler e dialogar conosco.

Giovana: Se eu tivesse que escolher uma palavra para resumir o curso, esta palavra seria fertilidade, pois acredito que ela sintetiza os impulsos de criatividade e produtividade que emergiram durante as aulas e se materializaram nesta publicação (e também em outras que acabaram de sair, como a resenha do livro de Mattingly escrita pela Júlia, ou que ainda estão sendo gestadas pelas estudantes). A meu ver, fertilidade evoca ainda a fusão de diferentes elementos, que resulta no advento do novo a partir de uma relação de cooperação. Como sabemos, as fontes desta capacidade são disputadas por diferentes atores, por diversas razões, há uns bons séculos. Em Calibã e a Bruxa (2017), a pensadora e ativista Silvia Federici nos mostra como o pensamento organicista e sexista historicamente vem sendo formulado e reformulado com propósitos desabonadores do feminino. Ela escreve o seguinte sobre uma formulação da primeira metade do século XVI:

Rejeitando a tradicional exaltação cristã da castidade, os reformadores valorizavam o casamento, a sexualidade e até mesmo as mulheres, por sua capacidade reprodutiva. As mulheres são "necessárias para produzir o crescimento da raça humana", reconheceu Lutero, refletindo que, "quaisquer que sejam suas debilidades, as mulheres possuem uma virtude que anula todas elas: possuem um útero e podem dar à luz" (King, 1991, p. 115, apud Federici, 2017, p. 171).

Giovana: Então, nesta boa hora, desejo que as ideias-sementes aqui reunidas sejam capazes - cada uma a sua maneira - de alargar e deformar os estreitos limites dessa definição fisiológica (aprisionadora) de útero, em direção a um horizonte de possibilidades em aberto, ao modo de uma matriz de pensamento mais plural e generosa e, portanto, mais potente. E também deixo aqui registrada a minha gratidão e admiração por Rosa e Soraya, interlocutoras reluzentes na academia e na vida, e pelas demais colegas do curso, que contribuíram com a ampliação dos meus horizontes acadêmicos e extra-acadêmicos. 
Rosamaria: Para mim, estar em curso de pós-graduação na Antropologia e, ao mesmo tempo, encontrar as minhas alunas da Saúde Pública entre suas cadeiras, foi uma aventura fascinante. Foi um respiro no universo, às vezes, tão duro da academia. Primeiro, pela aventura de estudar, ler e pensar a partir de textos que pouco conhecemos, mas que gostaríamos de abraçar. Em segundo lugar por conta de ser um curso orientado pela espinha dorsal de minha trajetória acadêmica e profissional. Quando Soraya me convidou a compor o curso com ela e a chamá-lo de Antropologia dos Úteros, fiquei fascinada e por isso lhe sou tão grata. Essa minha amiga de todas as horas, com a qual costuro úteros dentro e fora da universidade, desde quando nos conhecemos no encontro da ABA em Boa Vista (RR) e depois na minha defesa de tese. Ela com as parteiras e eu com as mulheres de camadas médias. Aprendi muito com Soraya sobre dar aulas e oferecer um curso, sempre preocupada em (re)inventar nossos encontros e propor algo novo, que vazasse os formalismos pedagógicos das cátedras. Penso que fazemos antropologia juntas, mas também damos a ela o nosso recorte autoral e feminista. Giovana tem sido uma interlocutora incrível, parceira de novas aventuras entre textos, grupos de trabalho e troca de dados de campo. Fico feliz que o campo da antropologia do parto hoje conte com sua experiência etnográfica e contraponto da etnologia. Por último, viera essa oportunidade: a de publicar um Dossiê e então subverter a escrita formal, mas não por isso menos científica, com esta Apresentação. Sou grata às duas por aceitarem iniciar estas páginas desse modo, com uma apresentação pessoal, engajada e definitivamente escrita a seis mãos. E igualmente a todas as estudantes, que me fizeram pensar e admirá-las em seu engajamento e dedicação. Espero realmente que gostem do que lhes espera e que a metáfora uterina atravesse a sua reflexão...

Um grande abraço das Organizadoras. 